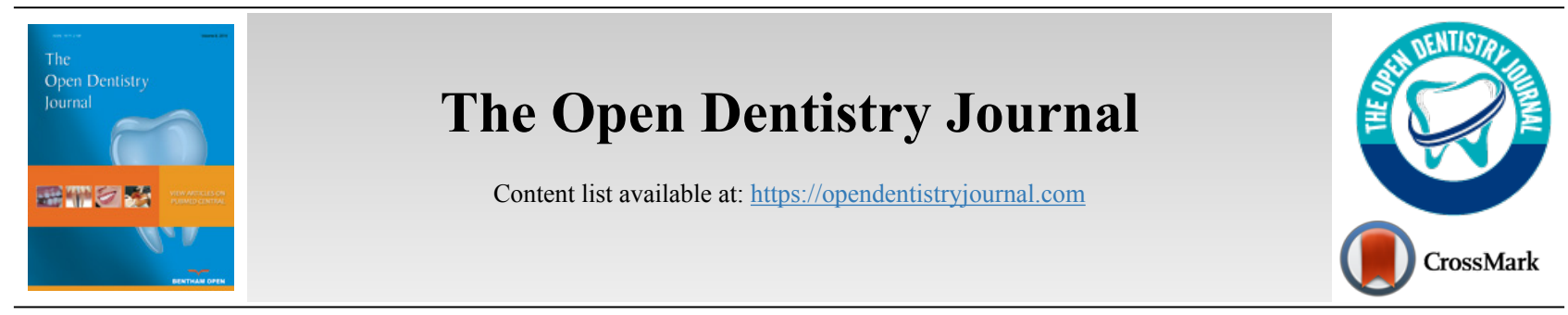

RESEARCH ARTICLE

\title{
Residual Dentin Thickness in Bifurcated Maxillary Premolars after Cervical Preflaring Preparation: A CBCT Analysis
}

Gilberto Siebert Filho ${ }^{1}$, Orlando Aguirre Guedes ${ }^{2, *}$, Thiago Machado Pereira ${ }^{1}$, Fabio Luís Miranda-Pedro ${ }^{1}$, Andreza Maria Fábio Aranha ${ }^{1}$, Helder Fernandes de Oliveira ${ }^{2}$, Jesus Djalma Pécora ${ }^{3}$ and Álvaro Henrique Borges ${ }^{1}$

${ }^{1}$ Department of Endodontics, Dental School, University of Cuiabá, Cuiabá, Mato Grosso, Brazil

${ }^{2}$ Department of Endodontics, Dental School, Evangelical University of Goiás, Anápolis, Goiás, Brazil

${ }^{3}$ Department of Restorative Dentistry, Dental School, University of São Paulo, Ribeirão Preto, São Paulo, Brazil

\begin{abstract}
:
Objective:

This study evaluated the residual dentin thickness (RDT) of maxillary premolars after the use of different cervical preflaring (PF) drills by using cone-beam computed tomography (CBCT).

Methods:

Eighty bifurcated maxillary premolars were accessed and randomly divided into 5 groups ( $\mathrm{n}=16)$. PF was performed with Gates-Glidden \#1, \#2, and \#3 (group 1), Largo \#1 and \#2 (group 2), and LA Axxess \#20/.06 (group 3), \#35/.06 (group 4), and \#45/.06 (group 5). CBCT images were acquired before (preoperative) and after (postoperative) PF. Initial and final cervical dentin thickness was measured at the buccal, palatal, mesial, and distal aspects, $0.5 \mathrm{~mm}$ coronally to the furcation, on both buccal and palatal roots, using CBCT's image analysis software. The percentage of removed dentin after PF preparation was also calculated. Data were analyzed using ANOVA followed by Tukey's test at a significance level of $P<0.05$.

Results:

No statistically significant differences were found among the groups for preoperative or postoperative RDT ( $P>0.05$ ). LA Axxess \#20/.06 (group 3) removed significantly less cervical dentin at all root canal aspects on both buccal and palatal roots. The mesial aspect of the buccal root and distal aspect of the palatal root were significantly reduced after the use of LA Axxess \#45/.06 (group 5) and Largo \#1 and \#2 drills (group 2), respectively $(P<0.05)$.

Conclusion:

PF in bifurcated maxillary premolars should be performed with LA Axxess instrument \#20/.06. The use of Gates-Glidden \#1, \#2, and \#3, Largo \#1 and \#2, and LA Axxess \#45/.06 drills should be done with caution.
\end{abstract}

Keywords: Bifurcated maxillary premolars, Cervical preflaring, Cone-beam computed tomography, Coronal flaring, Residual dentin thickness, Vertical root fracture.

\begin{tabular}{|l|l|l|l}
\hline Article History & Received: April 4, 2021 & Revised: July 16, 2021 & Accepted: July 28, 2021 \\
\hline
\end{tabular}

\section{INTRODUCTION}

Contemporary guidelines for cleaning, shaping, and disinfection of root canals emphasize the importance of the removal of dentin interferences along the cervical and middle thirds prior to apical instrumentation [1]. An adequate preflaring (PF) improves the determination of the anatomic

\footnotetext{
Address correspondence to this author at the Department of Endodontics, Dental School, Evangelical University of Goiás, Av. Universitária, Km 3,5, Cidade Universitária, 75083-515, Anápolis, Goiás, Brazil; Tel: +55 62 3310-6630;

E-mail: orlandoaguedes@gmail.com
}

diameter at the working length $[1,2]$, reduces the quantity of extrusion of debris [3] and the incidence of root dentin defects [4] during root canal preparation. On the other hand, an excessive dentin removal during PF may pose a risk to root perforation or even result in weakened root canal walls [5 - 10]. The residual dentin thickness (RDT) has been pointed out as the most important factor for root resistance against vertical root fracture (VRF) [11], which has been identified as the most common cause for the loss of endodontically treated teeth [11].

Maxillary premolars have complex and variable root and 
root canal morphology $[12,13]$. The presence of bifurcated roots with variable degree of curvature, narrow furcation entrance, deep mesial concavities, various pulp cavity configurations, and multiple canals and apical foramina [14, 15] makes the endodontic management of these teeth a real challenge $[12,15]$. Furcation groove on the palatal aspect of the buccal root is another relevant anatomic feature, commonly observed in bifurcated maxillary premolars $[12,14,16]$. The existence of a furcation groove has clinical importance for endodontic and prosthodontic treatment planning [12, 14] because its presence may result in inconsistent wall thickness at the different aspects of the root $[1,13,15]$, which could predispose to the occurrence of unpleasant operative accidents [17].

A considerable number of studies have been developed with the purpose of evaluating the effect of endodontic and prosthetic procedures on RDT [1, 5, 18 - 21]. A significant amount of information is derived from investigations on maxillary or mandibular molars [6 - 10, 19 - 23], which may not be fully applicable to other dental groups, since each tooth has its own features [15]. One of the main concerns, even for most experienced clinicians, is which PF instrument could create an increased risk for root perforation or creation of weakened root canal walls [24], especially in teeth presenting oval roots, in which the mesiodistal diameter is narrower than the buccolingual diameter, such as in maxillary premolars [1, 17]. Until now, there is no consensus about the clinical and radiographic parameters that should be considered when choosing the type and size of the instrument for the enlargement of cervical and middle thirds [5], which means that in daily clinical practice, the choice of PF instrument has been based on personal preference.

Studies regarding the RDT on maxillary premolars have focused on the comparison of different instrumentation techniques, the impact of post space preparation, or the morphologic analysis of the furcation groove $[1,12,14,16,17$, 25]. To date, no study has been developed to assess RDT after $\mathrm{PF}$ in maxillary premolars. Thus, this study evaluated the cervical dentin thickness of bifurcated maxillary premolars before and after the use of Gates-Glidden (GG), Largo, and LA Axxess drills by using cone-beam computed tomography $(\mathrm{CBCT})$. The null hypotheses tested were that RDT and the percentage of removed dentin do not vary as a function of the $\mathrm{PF}$ instrument.

\section{MATERIALS AND METHODS}

Bifurcated maxillary first and second premolars were obtained from the institutional tooth bank, radiographed in both buccolingual and mesiodistal directions and stored in $0.1 \%$ thymol solution (ProLab, São Paulo, SP, Brazil). Initially, teeth presenting fully-formed apices, bifurcation at the junction of the cervical and middle thirds, no caries, no restoration, no calcifications, no internal or external root resorptions, no dental posts or prosthetic crowns, and no prior endodontic treatment, were selected. Ethnicity, age, and gender of the donors were unknown.

All selected teeth were mounted on cylindrical molds embedded in silicone rubber (Cascola, Diadema, SP, Brazil) with their buccal surface in the anteroposterior position. Preoperative (before cervical PF) CBCT images (PreXion 3D Inc., San Mateo, CA, USA) were obtained using the following parameters: thickness, $0.1 \mathrm{~mm}$ (dimensions, $1.17 \mathrm{~mm} \times 1.57$ $\mathrm{mm} \times 1.925 \mathrm{~mm}$ ); field of view, $56.00 \mathrm{~mm}$; voxel, $0.100 \mathrm{~mm}$; tube voltage, $90 \mathrm{kVp}$; and tube current, $4 \mathrm{~mA}$. The exposure time was $33.5 \mathrm{~s}$. CBCT images were transferred to a computer and analyzed for increased tooth standardization. Only teeth with root curvature radius $>8 \mathrm{~mm}$ [26], root lengths of 21-22 $\mathrm{mm}$ (distance from the respective cusp to the apical foramen), and root trunk measuring 2.5-3.5 mm (distance from the pulp chamber floor to the furcation) were selected. A total of 80 bifurcated maxillary premolars were used in this study.

Initial cervical dentin thickness was measured at the buccal, mesial, distal, and palatal aspects of both buccal and palatal roots on axial cross-sections obtained at $0.5 \mathrm{~mm}$ coronally to the furcation. All measurements were performed using PreXion 3D Viewer software (TeraRecon Inc., Foster City, CA, USA), with initial settings including unchecked RaySum mode, window width of 500, and window level of 600 . The measurement direction followed the displayed cross lines mesiodistally and buccopalatally and was taken from the external limit of the root canal to the external root surface. The shortest distance from the root canal wall to the root surface was recorded. Each measurement was repeated three times, and the average was used.

After preoperative CBCT image acquisition, standard access cavities were performed using a $\# 1013$ bur (KG Sorensen, Barueri, SP, Brazil) in a high-speed handpiece (Kavo Ind. Com. Ltda., Joinville, SC, Brazil). Access was refined using a \#3083 bur (KG Sorensen) within the pulp chamber to obtain straight-line access to the buccal and palatal canal orifices. The pulp chamber and root canals were irrigated with $2 \mathrm{~mL}$ of $2.5 \%$ sodium hypochlorite $(\mathrm{NaOCl}$; Rioquímica, São José do Rio Preto, SP, Brazil) using a 5-mL disposable syringe (Ultradent Products Inc., South Jordan, UT, USA) and a 29gauge needle (NaviTip; Ultradent Products Inc.). The root canals were explored with \#10 and \#15 K-Files (Sirona Dentsply, Ballaigues, Switzerland), which were inserted passively until their tips became visible at the apical foramen. The teeth were then randomly divided into 5 groups $(n=16)$, according to the instrument used for cervical PF: Group 1: Gates-Glidden \#1 (0.50 mm), \#2 (0.70 mm), and \#3 (0.90 mm) (Sirona Dentsply); Group 2: Largo \#1 (0.70 mm) and \#2 (0.90 $\mathrm{mm}$ ) (Sirona Dentsply); Group 3: LA Axxess \#20/.06 (SybronEndo, Glendora, CA, USA); Group 4: LA Axxess \#35/.06 (SybronEndo); and Group 5: LA Axxess \#45/.06 (SybronEndo). The drills were used in a low-speed handpiece (Kavo) at 15,000 to 20,000 rpm and in strict accordance with the manufacturers' instructions. The straight up-and-down motion was used in the GG group [22], whereas the antifurcation and anticurvature filing motions were used in the Largo and LA Axxess groups [8]. In the GG and Largo groups, cervical PF started with small-diameter drills, followed by those with larger diameters (serial sequence) [5]. The instruments were used to a maximum depth of $2 / 3$ thirds of the tooth length, with a maximum depth of $5 \mathrm{~mm}$ from the root canal orifice. Before using each drill, and at the change of drills, the root canals were irrigated with $2 \mathrm{~mL}$ of $2.5 \% \mathrm{NaOCl}$ 
(Rioquímica) using a 29-gauge needle (Ultradent Products Inc.). A single operator, an endodontist with more than 10 years of experience, performed all root canal procedures. Each drill was used to preflaring 5 teeth and then discarded.

After cervical PF preparation, postoperative CBCT images were obtained, and the RDT was assessed using the same parameters described previously. A single examiner, an oral and maxillofacial radiologist with experience in interpreting CBCT exams, performed the preoperative and postoperative measurements twice with a 7-day interval. The examiner was blind to group allocation.

\subsection{Statistical Analysis}

The $\mathrm{R}$ software ( $\mathrm{R}$ version 3.3.2, R Core Team, Vienna, Austria) was used for statistical analysis. Kolmogorov-Smirnov and Levene tests were used to test normality and homogeneity. Comparisons between the groups were realized by analysis of variance (ANOVA) test followed by Tukey's test at a significance level of $P<0.05$. Intraexaminer agreement was assessed by kappa statistics in $10 \%$ of the sample.

\section{RESULTS}

Intraexaminer agreement was excellent for both preoperative $(\mathrm{kappa}=0.85)$ and postoperative $(\mathrm{kappa}=0.89)$ measurements. Table 1 shows the results for dentin thickness on preoperative CBCT images. The initial dentin thickness on the buccal root ranged from $1.57 \mathrm{~mm}$ (distal aspect) to 5.56 $\mathrm{mm}$ (palatal aspect), and on the palatal root from $1.41 \mathrm{~mm}$ (distal aspect) to $5.38 \mathrm{~mm}$ (buccal aspect). All groups were anatomically comparable since no statistically significant difference was observed in the buccal and palatal root canals for initial cervical dentin thickness (each root canal aspect separately) $(P>0.05)$. Table 2 shows the results for dentin thickness on postoperative CBCT images. Although, the lowest values of the RDT were observed in the mesial of group 5 (LA Axxess \#45/.06 group; $1.33 \pm 0.30$;) and distal of group 2 (Largo \#1 and \#2;1.33 \pm 0.20 ) aspects of the buccal root canal and distal aspect of group 2 (Largo \#1 and \#2 group; $1.16 \pm$ 0.19 ) of a palatal root canal, no significant difference was observed among groups (each root canal aspect separately) $(\mathrm{P}>0.05)$. Table 3 shows the results of percentage reduction in each group from before to after cervical PF. Statistically significant differences among groups were observed. LA Axxess \#20/.06 (group 3) removed significantly less cervical dentin at all root aspects on both buccal and palatal root canals. The mesial aspect of the buccal root and distal aspect of the palatal root were significantly reduced when prepared with LA Axxess \#45/.06 (group 5; $26.92 \pm 3.44$ ) and Largo \#1 and \#2 (group 2; $33.79 \pm 3.42$ ), respectively (Table 3).

Table 1. Means ( $\mathrm{mm}$ ) and standard deviation of cervical dentin thickness on preoperative (before cervical preflaring) cone beam computed tomography images in each group at the buccal, mesial, distal and palatal aspects of buccal and palatal root canals.

\begin{tabular}{|c|c|c|c|c|c|c|c|c|}
\hline \multicolumn{5}{|c|}{ Buccal Root } & \multicolumn{4}{|c|}{ Palatal Root } \\
\hline Group & Buccal & Mesial & Distal & Palatal & Palatal & Mesial & Distal & Buccal \\
\hline 1 & $2.08 \pm 0.31^{\mathrm{A}, \mathrm{a}}$ & $1.75 \pm 0.18^{\mathrm{B}, \mathrm{a}}$ & $1.74 \pm 0.23^{\mathrm{C}, \mathrm{a}}$ & $5.56 \pm 0.66^{\mathrm{D}, \mathrm{b}}$ & $2.12 \pm 0.17^{\mathrm{E}, \mathrm{a}}$ & $1.57 \pm 0.25^{\mathrm{F}, \mathrm{b}}$ & $1.55 \pm 0.22^{\mathrm{G}, \mathrm{b}}$ & $5.38 \pm 0.70^{\mathrm{H}, \mathrm{c}}$ \\
\hline 2 & $1.93 \pm 0.23^{\mathrm{A}, \mathrm{a}}$ & $1.66 \pm 0.23^{\mathrm{B}, \mathrm{a}}$ & $1.70 \pm 0.19^{\mathrm{C,a}}$ & $5.38 \pm 0.67^{\mathrm{D}, \mathrm{b}}$ & $2.00 \pm 0.45^{\mathrm{E}, \mathrm{a}}$ & $1.55 \pm 0.24^{\mathrm{Faa}}$ & $1.45 \pm 0.15^{\mathrm{G}, \mathrm{a}}$ & $5.07 \pm 0.47^{\mathrm{H}, \mathrm{b}}$ \\
\hline 3 & $1.90 \pm 0.20^{\mathrm{A}, \mathrm{a}}$ & $1.58 \pm 0.25^{\mathrm{B}, \mathrm{a}}$ & $1.57 \pm 0.22^{\mathrm{C}, \mathrm{a}}$ & $5.01 \pm 0.21^{\mathrm{D}, \mathrm{b}}$ & $2.06 \pm 0.18^{\mathrm{E}, \mathrm{a}}$ & $1.66 \pm 0.32^{\mathrm{F}, \mathrm{a}}$ & $1.55 \pm 0.34^{\mathrm{G}, \mathrm{a}}$ & $5.34 \pm 1.34^{\mathrm{H}, \mathrm{b}}$ \\
\hline 4 & $1.99 \pm 0.31^{\mathrm{A}, \mathrm{a}}$ & $1.75 \pm 0.29^{\mathrm{B}, \mathrm{a}}$ & $1.67 \pm 0.15^{\mathrm{c}, \mathrm{a}}$ & $5.01 \pm 0.21^{\mathrm{D}, \mathrm{b}}$ & $2.08 \pm 0.36^{\mathrm{E}, \mathrm{a}}$ & $1.53 \pm 0.34^{\mathrm{Fa}, \mathrm{b}}$ & $1.41 \pm 0.19^{\mathrm{G}, \mathrm{b}}$ & $5.14 \pm 0.38^{\mathrm{H}, \mathrm{c}}$ \\
\hline 5 & $1.99 \pm 0.37^{\mathrm{A}, \mathrm{a}}$ & $1.82 \pm 0.17^{\mathrm{B}, \mathrm{a}}$ & $1.75 \pm 0.24^{\mathrm{C,a}}$ & $5.29 \pm 0.46^{\mathrm{D}, \mathrm{b}}$ & $2.10 \pm 0.46^{\mathrm{E}, \mathrm{a}}$ & $1.72 \pm 0.43^{\mathrm{F}, \mathrm{a}}$ & $1.70 \pm 0.36^{\mathrm{G}, \mathrm{a}}$ & $5.28 \pm 0.38^{\mathrm{H}, \mathrm{b}}$ \\
\hline
\end{tabular}

Group 1: Gates-Glidden \#1, \#2 and \#3; Group 2: Largo \#1 and \#2; Group 3: LA Axxess 20/.06; Group 4: LA Axxess 35/.06; Group 5: LA Axxess 45/.06.

Capital letters compare groups in vertical lines and lower-case letters in horizontal lines.

Tukey test categories with the same letter are not statistically different from each other $(P>0.05)$.

Table 2. Means (mm) and standard deviation of cervical dentin thickness on postoperative (after cervical preflaring) cone beam computed tomography images in each group at the buccal, mesial, distal and palatal aspects of buccal and palatal root canals.

\begin{tabular}{|c|c|c|c|c|c|c|c|c|}
\hline \multicolumn{5}{|c|}{ Buccal Root } & \multicolumn{4}{|c|}{ Palatal Root } \\
\hline Group & Buccal & Mesial & Distal & Palatal & Palatal & Mesial & Distal & Buccal \\
\hline 1 & $1.79 \pm 0.31^{\mathrm{A}, \mathrm{a}}$ & $1.51 \pm 0.25^{\mathrm{B}, \mathrm{a}}$ & $1.45 \pm 0.12^{\mathrm{C}, \mathrm{a}}$ & $4.95 \pm 0.37^{\mathrm{D}, \mathrm{b}}$ & $1.98 \pm 0.19^{\mathrm{E}, \mathrm{a}}$ & $1.46 \pm 0.23^{\mathrm{F}, \mathrm{b}}$ & $1.39 \pm 0.27^{\mathrm{G}, \mathrm{b}}$ & $5.25 \pm 0.67^{\mathrm{H}, \mathrm{c}}$ \\
\hline 2 & $1.72 \pm 0.45^{\mathrm{A}, \mathrm{a}}$ & $1.44 \pm 0.36^{\mathrm{B}, \mathrm{a}}$ & $1.33 \pm 0.20^{\mathrm{C}, \mathrm{a}}$ & $5.19 \pm 0.41^{\mathrm{D}, \mathrm{b}}$ & $1.82 \pm 0.38^{\mathrm{E}, \mathrm{a}}$ & $1.33 \pm 0.42^{\mathrm{F}, \mathrm{a}, \mathrm{b}}$ & $1.16 \pm 0.19^{\mathrm{G}, \mathrm{b}}$ & $4.96 \pm 0.46^{\mathrm{H}, \mathrm{c}}$ \\
\hline 3 & $1.83 \pm 0.38^{\mathrm{A}, \mathrm{a}}$ & $1.44 \pm 0.31^{\mathrm{B}, \mathrm{a}}$ & $1.54 \pm 0.22^{\mathrm{C}, \mathrm{a}}$ & $4.98 \pm 0.53^{\mathrm{D}, \mathrm{b}}$ & $2.04 \pm 0.44^{\mathrm{E}, \mathrm{a}}$ & $1.56 \pm 0.42^{\mathrm{F}, \mathrm{a}}$ & $1.53 \pm 0.17^{\mathrm{G}, \mathrm{a}}$ & $5.24 \pm 1.37^{\mathrm{H}, \mathrm{b}}$ \\
\hline 4 & $1.87 \pm 0.29^{\mathrm{A}, \mathrm{a}}$ & $1.69 \pm 0.21^{\mathrm{B}, \mathrm{a}}$ & $1.54 \pm 0.17^{\mathrm{C}, \mathrm{a}}$ & $4.92 \pm 0.24^{\mathrm{D}, \mathrm{b}}$ & $1.97 \pm 0.19^{\mathrm{E}, \mathrm{a}}$ & $1.38 \pm 0.33^{\mathrm{F}, \mathrm{b}}$ & $1.40 \pm 0.25^{\mathrm{G}, \mathrm{b}}$ & $5.09 \pm 0.55^{\mathrm{H}, \mathrm{c}}$ \\
\hline 5 & $1.82 \pm 0.17^{\mathrm{A}, \mathrm{a}}$ & $1.33 \pm 0.30^{\mathrm{B}, \mathrm{a}}$ & $1.44 \pm 0.36^{\mathrm{C}, \mathrm{a}}$ & $4.95 \pm 0.37^{\mathrm{D}, \mathrm{b}}$ & $1.94 \pm 0.31^{\mathrm{E}, \mathrm{a}}$ & $1.23 \pm 0.36^{\mathrm{F}, \mathrm{a}, \mathrm{b}}$ & $1.24 \pm 0.24^{\mathrm{G}, \mathrm{b}}$ & $4.97 \pm 0.62^{\mathrm{H}, \mathrm{c}}$ \\
\hline
\end{tabular}

Group 1: Gates-Glidden \#1, \#2 and \#3; Group 2: Largo \#1 and \#2; Group 3: LA Axxess 20/.06; Group 4: LA Axxess 35/.06; Group 5: LA Axxess 45/.06.

Capital letters compare groups in vertical lines and lower-case letters in horizontal lines.

Tukey test categories with the same letter are not statistically different from each other $(P>0.05)$. 
Table 3. Mean and standard deviation of percentage reduction in each group at the buccal, mesial, distal and palatal aspects of buccal and palatal root canals.

\begin{tabular}{|c|c|c|c|c|c|c|c|c|}
\hline \multicolumn{5}{|c|}{ Buccal Root } & \multicolumn{4}{|c|}{ Palatal Root } \\
\hline Group & Buccal & Mesial & Distal & Palatal & Palatal & Mesial & Distal & Buccal \\
\hline 1 & $13.94 \pm 0.18^{\mathrm{A}, \mathrm{a}}$ & $13.71 \pm 0.16^{\mathrm{A}, \mathrm{a}}$ & $16.60 \pm 0.19^{\mathrm{A}, \mathrm{b}}$ & $13.94 \pm 0.15^{\mathrm{A}, \mathrm{a}}$ & $6.60 \pm 0.95^{\mathrm{A}, \mathrm{a}}$ & $7.00 \pm 0.98^{\mathrm{A}, \mathrm{a}}$ & $10.32 \pm 1.15^{\mathrm{A}, \mathrm{b}}$ & $2.41 \pm 0.33^{\mathrm{A}, \mathrm{C}}$ \\
\hline 2 & $10.88 \pm 0.17^{\mathrm{B}, \mathrm{a}}$ & $13.25 \pm 0.16^{\mathrm{B}, \mathrm{b}}$ & $21.76 \pm 0.26^{\mathrm{B}, \mathrm{c}}$ & $10.88 \pm 0.14^{\mathrm{B}, \mathrm{a}}$ & $9.00 \pm 1.02^{\mathrm{B}, \mathrm{a}}$ & $14.19 \pm 1.62^{\mathrm{B}, \mathrm{b}}$ & $33.79 \pm 3.42^{\mathrm{B}, \mathrm{c}}$ & $2.16 \pm 0.38^{\mathrm{A}, \mathrm{d}}$ \\
\hline 3 & $3.68 \pm 0.42^{\mathrm{C}, a}$ & $8.86 \pm 0.11^{\mathrm{C}, \mathrm{b}}$ & $1.91 \pm 0.22^{\mathrm{C}, \mathrm{c}}$ & $0.59 \pm 0.07^{\mathrm{C,d}}$ & $0.97 \pm 0.14^{\mathrm{C}, \mathrm{a}}$ & $6.02 \pm 0.83^{\mathrm{A}, \mathrm{b}}$ & $1.30 \pm 0.18^{\mathrm{C}, \mathrm{a}}$ & $1.87 \pm 0.22^{\mathrm{A}, \mathrm{C}}$ \\
\hline 4 & $6.03 \pm 0.83^{\mathrm{D}, \mathrm{a}}$ & $17.36 \pm 1.88^{\mathrm{D}, \mathrm{b}}$ & $7.78 \pm 0.99^{\mathrm{D}, \mathrm{c}}$ & $1.79 \pm 0.21^{\mathrm{D,d}}$ & $5.28 \pm 0.64^{\mathrm{A}, \mathrm{a}}$ & $9.80 \pm 1.21^{\mathrm{C}, \mathrm{b}}$ & $0.70 \pm 0.09^{\mathrm{D}, \mathrm{c}}$ & $0.97 \pm 0.13^{\mathrm{B}, \mathrm{d}}$ \\
\hline 5 & $8.54 \pm 0.92^{\mathrm{E}, \mathrm{a}}$ & $26.92 \pm 3.44^{\mathrm{E}, \mathrm{b}}$ & $17.71 \pm 2.01^{\mathrm{A}, \mathrm{c}}$ & $6.42 \pm 0.88^{\mathrm{E}, \mathrm{d}}$ & $7.61 \pm 0.84^{\mathrm{A}, \mathrm{a}}$ & $28.48 \pm 3.12^{\mathrm{D}, \mathrm{b}}$ & $27.05 \pm 2.92^{\mathrm{E}, \mathrm{b}}$ & $5.87 \pm 0.64^{\mathrm{C}, \mathrm{c}}$ \\
\hline
\end{tabular}

Group 1: Gates-Glidden \#1, \#2 and \#3; Group 2: Largo \#1 and \#2; Group 3: LA Axxess 20/.06; Group 4: LA Axxess 35/.06; Group 5: LA Axxess 45/.06.

Capital letters compare groups in vertical lines and lower-case letters in horizontal lines.

Tukey test categories with the same letter are not statistically different from each other $(P>0.05)$.

\section{DISCUSSION}

Although many advantages can be obtained by performing cervical PF $[4,9,10,17]$, it has not yet been established which cervical enlargement is the minimum and yet large enough to allow appropriate cleaning, shaping, disinfection, and threedimensional filling of the root canal system [5]. In this way, some operative procedural errors and post-treatment complications $[11,14]$ can occur during and or due to this clinical step, mainly as a result of excessive removal of coronal and radicular tooth structures [1]. For these reasons, cervical $\mathrm{PF}$ instruments that promote excessive removal of cervical tooth structure should be avoided [18] and a balance between cervical PF and dentin thickness should be reached [24]. The present study aimed to compare the effect of GG, Largo and LA Axxess drills on cervical dentin thickness of bifurcated maxillary premolars by using CBCT. The results showed that there were no significant differences between the PF drills in relation to the residual cervical dentin thickness (Table 2). However, there were significant differences regarding the percentage of removed dentin (Table 3 ). Therefore, the tested null hypotheses were partially rejected.

In the present study, CBCT was used to obtain images and specialized software (PreXion 3D Viewer) was used to measure cervical dentin thickness before and after PF and, consequently, to determine the amount of cervical root dentin removed [9, 17, 27, 28]. This methodological design was based on previously published studies that demonstrated the applicability and accuracy of CBCT in the evaluation of RDT [8 - 10, 23]. CBCT is a highly accurate and reproducible method to investigated, quantitatively and qualitatively, the root canal system without destroying the specimen $[8,10,25$, 26]. The information generated by CBCT is higher than those obtained by periapical radiography $[15,23]$ and can be safely compared with those obtained from histologic sections [28] and Micro-CT studies [21]. Unfortunately, there is the possibility of interference from artifacts in CBCT [27]. The presence of highdensity intracanal materials, such as root canal sealers and intraradicular posts, may result in low image quality and poor image contrast [29], which may preclude the measurement of RDT. A new CBCT software package (e-Vol DX; CDT Software, Bauru, SP, Brazil) was recently developed with the purpose of overcoming the limitations of CBCT. The software includes features such as specific brightness and contrast adjustment, custom image thickness control, custom image sharpening filter, advanced noise reduction algorithm, and capability to recognize data from different CBCT scanners and apply them to the specific scanner [29]. This, results in timesaving during image navigation and high-resolution image capture. The e-Vol DX potential for clinical and research applications has been initially evaluated [27, 29] with promising results.

Previous studies investigating root thickness have used different assessment depths, including 2, 4, and $6 \mathrm{~mm}$ from the cemento-enamel junction [30], 1.5 and $3 \mathrm{~mm}$ from the furcation area [23], 2, 4, and $6 \mathrm{~mm}$ from the apex [1], $2 \mathrm{~mm}$ apical to the furcation [8], 1, 2, 3, and $4 \mathrm{~mm}$ below the furcation level $[5,10,17], 3$ and $4 \mathrm{~mm}$ from the canal entrance $[7,9,19], 5 \mathrm{~mm}$ above the apex and $1 \mathrm{~mm}$ below and above the furcation [25], hindering the comparison of results. Some studies have reported that, in maxillary premolars, the area within $1 \mathrm{~mm}$ above to $2 \mathrm{~mm}$ below the furcation is associated with a greater decrease in dentin thickness after endodontic procedures $[17,25]$. In addition, this region includes important anatomic structures, such as the furcation groove of the buccal roots [12]. Based on that assumption, axial cross-sections of the root were obtained in this study at $0.5 \mathrm{~mm}$ coronally to the furcation to analyze the RDT of all 4 walls of the root canal.

Different instruments have been developed and suggested for PF [8 - 10, 23]. In the present study, GG and Largo drills were chosen because they are widely used in cervical PF and post space preparation $[5,8]$, while LA Axxess drills were chosen because they have been recently introduced in the market and there are few studies on the use of these instruments [2 - 4, 25]. GG \#3 was chosen based on previous studies that used this diameter during the cervical PF of teeth with a narrow mesiodistal diameter $[8,17,19,23]$. Largo \#2 with the same diameter of GG \#3 was chosen. LA Axxess $20 / .06,35 / .06$, and 45/.06 were chosen because previous studies have demonstrated a more accurate relationship between file size and anatomic diameter after their use [2], as well as a smaller quantity of apical debris extrusion [3] and a lower incidence of root dentin defects during root canal preparation [4]. Regarding RDT, the sequence in which GG and Largo drills are used still represents a matter of controversy [6, 19]. While Coutinho-Filho et al. [6] observed greater remaining dentin/cementum thickness using GG burs in the crown-down sequence than in the serial sequence, Akhlaghi et al. [10] observed that, in the presence of appropriate initial root thickness, GG drills could be used in any sequence. The serial sequence was chosen in this study because it can be easily performed, is accessible to all operators and is the most 
widely used technique. Another point of discussion refers to the movements used with GG drills (straight up-and-down motion or anticurvature filing motion). Isom et al. [22] found that GG drills used in straight up-and-down motion removed more dentin at the level of the furcation of the mesial canals of mandibular molars. Wu et al. [5] observed that using GG drills with anticurvature pressure did not reduce the risk of root perforation in mandibular molars. In this study, GG drills were used in a straight up-and-down motion to reduce the risk of their shank fracture [8], whereas Largo and LA Axxess drills in an antifurcation and anticurvature filing motions, following the manufacturers' recommendations.

It has been demonstrated that the occurrence of VRF in endodontically treated teeth is directly related to the quantity and quality of remaining tooth tissues $[16,18]$. Therefore, at least $1 \mathrm{~mm}$ of root dentin should remain in all root aspects along its entire length after endodontic and prosthetic procedures $[1,30]$. In the present study, postoperative dentin thickness on the buccal root ranged from $1.33 \mathrm{~mm}$ (distal aspect) to $5.19 \mathrm{~mm}$ (buccal aspect), and on the palatal root from $1.16 \mathrm{~mm}$ (distal aspect) to $5.25 \mathrm{~mm}$ (palatal aspect). These results are similar to those reported by Mahran and AboEl-Fotouh [19] and Akhlaghi et al. [10] for the evaluation of the effect of ProTaper, HeroShaper, Race, and GG on RDT, in which adequate cervical wall thickness $(>1 \mathrm{~mm})$ was observed, but in contrast to those reported by Flores et al. [8] and Sousa et al. [9], who found RDT values lower than the recommended minimum of $1 \mathrm{~mm}$ after cervical preparation with GG, Largo, LA Axxess, CPdrill, and TripleGates burs. The difference in RDT values could be attributed to the use of different tooth types and to the variation in assessment depths. No significant differences were observed in RDT between the different PF drills tested $(\mathrm{P}>0.05)$ (Table 2), which is consistent with previous studies $[8,9,23]$.

Unfortunately, in the present study, the ethnicity, age, and gender of the donors were unknown. It could be pointed out as a limitation, since these factors have an influence on the volume ratio of the pulp cavity, in the diameter of the root canal orifices, and in the initial root thickness $[10,12,13,16]$.

The process of selecting a PF instrument should be dictated by both root and root canal morphologies of the involved tooth and the characteristics of the possible instrument [8]. In this sense, further studies should be developed to evaluate the impact of other instruments and techniques for PF in order to obtain a consistent, predictable and reproducible cervical enlargement with less iatrogenic damage.

\section{CONCLUSION}

Cervical PF in bifurcated maxillary premolars should be performed with LA Axxess instrument 20/.06. The use of GG $\# 1$, \#2, and \#3, Largo \#1 and \#2, and LA Axxess 35/.06 and 45/.06 drills should be done with caution.

\section{ETHICS APPROVAL AND CONSENT TO PARTICIPATE}

The study protocol was revised and approved by the Research Ethics Committee of the University of Cuiabá, Cuiabá, MT, Brazil (protocol number 91014218.1.0000.5165).

\section{HUMAN AND ANIMAL RIGHTS}

No animals were used in this research. All research procedures followed were in accordance with the ethical standards of the committee responsible for human experimentation (institutional and national), and with the Helsinki Declaration of 1975 , as revised in 2008 (http://www.wma.net/en/20activities/10ethics/10helsinki/)?.

\section{CONSENT FOR PUBLICATION}

The participants provided written informed consent to be involved in this study.

\section{AVAILABILITY OF DATA AND MATERIALS}

The data supporting the findings of the article is available in the [University of Cuiabá] at [https://repositorio.pgsskroton.com/bitstream/123456789/3064/ 1/Gilberto\%20Siebert\%20Filho.pdf].

\section{FUNDING}

None.

\section{CONFLICT OF INTEREST}

The authors declare no conflict of interest, financial or otherwise.

\section{ACKNOWLEDGEMENTS}

Declared none.

\section{REFERENCES}

[1] Katz A, Wasenstein-Kohn S, Tamse A, Zuckerman O. Residual dentin thickness in bifurcated maxillary premolars after root canal and dowel space preparation. J Endod 2006; 32(3): 202-5. [http://dx.doi.org/10.1016/j.joen.2005.10.048] [PMID: 16500226]

[2] Ibelli GS, Barroso JM, Capelli A, Spanó JC, Pécora JD. Influence of cervical preflaring on apical file size determination in maxillary lateral incisors. Braz Dent J 2007; 18(2): 102-6.

[http://dx.doi.org/10.1590/S0103-64402007000200003] [PMID: 17982547]

[3] Borges AH, Pereira TM, Porto AN, et al. The influence of cervical preflaring on the amount of apically extruded debris after root canal preparation using different instrumentation systems. J Endod 2016; 42(3): 465-9.

[http://dx.doi.org/10.1016/j.joen.2015.10.010] [PMID: 26614016]

[4] Borges AH, Damião MS, Pereira TM, et al. Influence of cervical preflaring on the incidence of root dentin defects. J Endod 2018; 44(2): 286-91.

[http://dx.doi.org/10.1016/j.joen.2017.09.021] [PMID: 29208400]

[5] Wu MK, van der Sluis LW, Wesselink PR. The risk of furcal perforation in mandibular molars using Gates-Glidden drills with anticurvature pressure. Oral Surg Oral Med Oral Pathol Oral Radiol Endod 2005; 99(3): 378-82.

[http://dx.doi.org/10.1016/j.tripleo.2004.07.008] [PMID: 15716849]

[6] Coutinho-Filho T, De-Deus G, Gurgel-Filho ED, Rocha-Lima AC, Dias KR, Barbosa CA. Evaluation of the risk of a stripping perforation with Gates-Glidden drills: Serial versus crown-down sequences. Braz Oral Res 2008; 22(1): 18-24.

[http://dx.doi.org/10.1590/S1806-83242008000100004] [PMID: 18425240]

[7] Tabrizizadeh M, Reuben J, Khalesi M, Mousavinasab M, Ezabadi MG. Evaluation of radicular dentin thickness of danger zone in mandibular first molars. J Dent (Tehran) 2010; 7(4): 196-9. [PMID: 21998796]

[8] Flores CB, Montagner F, Gomes BP, Dotto GN, da Silva Schmitz M. Comparative assessment of the effects of Gates-Glidden, Largo, LAAxxess, and New Brazilian Drill CPdrill on coronal pre-enlargement: Cone-beam computed tomographic analysis. J Endod 2014; 40(4): 
571-4.

[http://dx.doi.org/10.1016/j.joen.2013.08.028] [PMID: 24666914]

[9] Sousa K, Andrade-Junior CV, Silva JM, Duarte MA, De-Deus G, Silva EJ. Comparison of the effects of TripleGates and Gates-Glidden burs on cervical dentin thickness and root canal area by using cone beam computed tomography. J Appl Oral Sci 2015; 23(2): 164-8. [http://dx.doi.org/10.1590/1678-775720130542] [PMID: 26018308]

[10] Akhlaghi NM, Bajgiran LM, Naghdi A, Behrooz E, Khalilak Z. The minimum residual root thickness after using ProTaper, RaCe and Gates-Glidden drills: A cone beam computerized tomography study. Eur J Dent 2015; 9(2): 228-33.

[http://dx.doi.org/10.4103/1305-7456.156833] [PMID: 26038655]

[11] Tamse A. Vertical root fractures in endodontically treated teeth: Diagnostic signs and clinical management. Endod Topics 2006; 13(1): 84-94.

[http://dx.doi.org/10.1111/j.1601-1546.2006.00200.x]

[12] Li J, Li L, Pan Y. Anatomic study of the buccal root with furcation groove and associated root canal shape in maxillary first premolars by using micro-computed tomography. J Endod 2013; 39(2): 265-8. [http://dx.doi.org/10.1016/j.joen.2012.10.003] [PMID: 23321243]

[13] Ahmad IA, Alenezi MA. Root and root canal morphology of maxillary first premolars: A literature review and clinical considerations. J Endod 2016; 42(6): 861-72.

[http://dx.doi.org/10.1016/j.joen.2016.02.017] [PMID: 27106718]

[14] Tamse A, Katz A, Pilo R. Furcation groove of buccal root of maxillary first premolars--A morphometric study. J Endod 2000; 26(6): 359-63. [http://dx.doi.org/10.1097/00004770-200006000-00012] [PMID: 11199755]

[15] Abella F, Teixidó LM, Patel S, Sosa F, Duran-Sindreu F, Roig M. Cone-beam computed tomography analysis of the root canal morphology of maxillary first and second premolars in a spanish population. J Endod 2015; 41(8): 1241-7.

[http://dx.doi.org/10.1016/j.joen.2015.03.026] [PMID: 25956606]

[16] Lammertyn PA, Rodrigo SB, Brunotto M, Crosa M. Furcation groove of maxillary first premolar, thickness, and dentin structures. J Endod 2009; 35(6): 814-7.

[http://dx.doi.org/10.1016/j.joen.2009.03.012] [PMID: 19482177]

[17] Harandi A, Mohammadpour Maleki F, Moudi E, Ehsani M, Khafri S. CBCT assessment of root dentine removal by gates-glidden drills and two engine-driven root preparation systems. Iran Endod J 2017; 12(1): 29-33.

[PMID: 28179920]

[18] Plotino G, Grande NM, Falanga A, Di Giuseppe IL, Lamorgese V, Somma F. Dentine removal in the coronal portion of root canals following two preparation techniques. Int Endod J 2007; 40(11): 852-8.

[http://dx.doi.org/10.1111/j.1365-2591.2007.01284.x] [PMID: 17697107]

[19] Mahran AH, AboEl-Fotouh MM. Comparison of effects of protaper, heroshaper, and gates glidden burs on cervical dentin thickness and root canal volume by using multislice computed tomography. J Endod 2008; 34(10): 1219-22.

[http://dx.doi.org/10.1016/j.joen.2008.06.022] [PMID: 18793924]
[20] Sant'Anna Júnior A, Cavenago BC, Ordinola-Zapata R, De-Deus G, Bramante CM, Duarte MA. The effect of larger apical preparations in the danger zone of lower molars prepared using the Mtwo and Reciproc systems. J Endod 2014; 40(11): 1855-9.

[http://dx.doi.org/10.1016/j.joen.2014.06.020] [PMID: 25127935]

[21] Xu J, He J, Yang Q, et al. Accuracy of cone-beam computed tomography in measuring dentin thickness and its potential of predicting the remaining dentin thickness after removing fractured instruments. J Endod 2017; 43(9): 1522-7.

[http://dx.doi.org/10.1016/j.joen.2017.03.041] [PMID: 28673490]

[22] Isom TL, Marshall JG, Baumgartner JC. Evaluation of root thickness in curved canals after flaring. J Endod 1995; 21(7): 368-71.

[http://dx.doi.org/10.1016/S0099-2399(06)80972-6] [PMID: 7499977]

[23] Homayoon A, Hamidi MR, Haddadi A, Madani ZS, Moudi E, Bijani A. Comparing the coronal flaring efficacy of five different instruments using cone-beam computed tomography. Iran Endod J 2015; 10(4): 263-7.

[PMID: 26525955]

[24] Duarte MA, Bernardes RA, Ordinola-Zapata R, Vasconcelos BC, Bramante CM, Moraes IG. Effects of Gates-Glidden, LA Axxess and orifice shaper burs on the cervical dentin thickness and root canal area of mandibular molars. Braz Dent J 2011; 22(1): 28-31.

[http://dx.doi.org/10.1590/S0103-64402011000100004] [PMID: 21519644]

[25] Mangal S, Mathew S, Sreenivasa Murthy BV, Nagaraja S, Dinesh K, Ramesh P. Cone-beam computed tomographic evaluation of remaining dentin thickness in bifurcated roots of maxillary first premolars after rotary instrumentation and post space preparation: An in vitro study. $\mathrm{J}$ Conserv Dent 2018; 21(1): 63-7.

[PMID: 29628650]

[26] Estrela C, Bueno MR, Barletta FB, et al. Identification of Apical and Cervical Curvature Radius of Human Molars. Braz Dent J 2015; 26(4): 351-6.

[http://dx.doi.org/10.1590/0103-64402013x0252] [PMID: 26312971]

[27] Estrela C, Couto GS, Bueno MR, et al. Apical foramen position in relation to proximal root surfaces of human permanent teeth determined by using a new cone-beam computed tomographic software. J Endod 2018; 44(11): 1741-8.

[http://dx.doi.org/10.1016/j.joen.2018.07.028] [PMID: 30266469]

[28] Michetti J, Maret D, Mallet JP, Diemer F. Validation of cone beam computed tomography as a tool to explore root canal anatomy. J Endod 2010; 36(7): 1187-90.

[http://dx.doi.org/10.1016/j.joen.2010.03.029] [PMID: 20630296]

[29] Bueno MR, Estrela C, Azevedo BC, Diogenes A. Development of a new cone-beam computed tomography software for endodontic diagnosis. Braz Dent J 2018; 29(6): 517-29.

[http://dx.doi.org/10.1590/0103-6440201802455] [PMID: 30517473]

[30] Bellucci C, Perrini N. A study on the thickness of radicular dentine and cementum in anterior and premolar teeth. Int Endod J 2002; 35(7): 594-606.

[http://dx.doi.org/10.1046/j.1365-2591.2002.00537.x]

[PMID: 12190899]

\section{(C) 2021 Filho et al.}

This is an open access article distributed under the terms of the Creative Commons Attribution 4.0 International Public License (CC-BY 4.0), a copy of which is available at: https://creativecommons.org/licenses/by/4.0/legalcode. This license permits unrestricted use, distribution, and reproduction in any medium, provided the original author and source are credited. 